\title{
As patentes como soluções científicas e tecnológicas aplicáveis a outros cenários
}

\author{
Sérgio Paulo Maravilhas Lopes \\ CETAC.MEDIA - Universidades do Porto e de Aveiro, Portugal \\ UFBA - ICI - Pesquisador de Post-Doc e bosista do PNPD/CAPES, Salvador, Bahia, Brasil
}

\section{COMUNICAÇÕES}

\begin{abstract}
Resumo
A utilização da informação de patentes, contendo os resultados das atividades de investigação e desenvolvimento com aplicação industrial, pode contribuir para o aumento da criatividade e suporte na resolução de problemas de investigação, potenciando a inovação através de novos produtos e processos daí decorrentes.

É possível utilizar a informação científico-técnica contida em bases de dados de patentes de acesso público gratuito, via Internet, como fonte de ideias permitindo desenvolver produtos e processos com base nessa informação.

A consulta da informação de patentes ajuda a evitar o desperdício de recursos materiais e financeiros, pois evita a reinvenção do que já existe e permite a realização de soluções sustentáveis, quer pelo aproveitamento de invenções não exploradas, como pela formulação de novos produtos com base em investigação e desenvolvimento já realizada, que pode ser adaptada a novas necessidades globais, gerando emprego, melhoria das condições sociais e económicas, protegendo o ambiente e seus recursos.

Desta forma, a informação de patentes, repositório de Ciência e Tecnologia, revela-se como uma fonte de estímulo à criatividade potenciadora de inovações que permitam responder aos desafios do presente e perspetivar um futuro mais rico para toda a humanidade através do crescimento económico e melhoria de vida da população.
\end{abstract}

\section{Palavras-chave}

Informação de patentes ; Inovação ; Criatividade ; Ciência ; Tecnologia ; Propriedade industrial ; Investigação e desenvolvimento

\section{Patents as scientific and technological solutions applicable to other scenarios}

\begin{abstract}
The use of patent information, containing the results of research and development activities with industrial application, may contribute to the increase of creativity and support in solving research problems, fostering innovation through new products and processes arising from that activity.

You can use the scientific and technical information contained in patent databases, with free public access via the Internet, as a source of ideas allowing to develop products and processes based on that information.

The consultation of patent information helps to avoid wasting material and financial resources, it prevents the reinvention of what already exists and allows the realization of sustainable solutions, either by the use of unexploited inventions or the formulation of new products based on research and development already donne, which can be adapted to new global needs, generating employment, improving social and economic conditions, protecting the environment and its resources. Thus, patent information, the repository of Science and Technology, reveals itself as a source of stimulation for creativity-enhancing innovations to respond to the challenges of the present and build a richer future for all mankind through economic growth and life improvement of the population.
\end{abstract}

Keywords

Patent information; Innovation ; Creativity ; Science ; Technology ; Industrial property ; Research and development 


\section{Introdução}

Atualmente, a informação é gerada e difundida a uma velocidade vertiginosa. Não só os produtos criados facilmente se tornam obsoletos ou desatualizados face ao ritmo constante de novas inovações, como novas empresas surgem a um ritmo alucinante para ocuparem o espaço deixado por explorar pelas empresas existentes que não souberam acompanhar a evolução tecnológica e as mudanças nos hábitos dos consumidores.

$\mathrm{Na}$ economia atual a riqueza gera-se através da criação de valor usando o conhecimento que provém de ideias inovadoras. Gerindo eficazmente a informação as ideias para futuros negócios emergem, dando origem a inovações que podem traduzir-se em vantagens competitivas para os seus detentores.

As empresas portuguesas não estão a utilizar com eficácia esse espólio de informação disponível, que tem várias vantagens estratégicas e de mercado (CARDOSO, 2006; DOORNBOS, GRAS, \& TOTH, 2003; ROLAND BERGER \& PARTNER, 1998).

Esta é, também, uma das conclusões do estudo de GODINHO (2003, 28, 29), que sugere como ação estratégica a "difusão de informação", procurando mostrar a importância de se encontrarem "meios para disseminar a enorme quantidade de informação constante nos repositórios nacionais e internacionais de $\mathrm{Pl}$ ".

Os documentos de patente geram informação científico-técnica, proveniente de qualquer país, passível de consulta recorrendo às possibilidades oferecidas pela Internet.

As vantagens ${ }^{1}$ oferecidas pela informação de patentes precisam de ser divulgadas de modo a incentivar a sua eficaz e eficiente utilização por parte dos investigadores e empresários portugueses (MARAVILHAS \& BORGES, 2011b; 2013).

Torna-se imperioso fomentar o seu uso e exploração, formando para a sua utilização.

Ao estimular a criatividade com menores custos de I\&D (MARAVILHAS, 2009), permitirá a introdução de inovações no mercado com tecnologias menos nocivas e mais eficientes (MARAVILHAS, 2012; 2013), vantagens de que todos podemos beneficiar.

Se existe um recurso onde ciência e tecnologia se fundem para estimular a inovação esse é, sem dúvida, a informação de patentes.

\section{A informação de patentes}

Para obter a proteção por patente, o requerente deve formalizar um pedido junto do INPI (Instituto Nacional da Propriedade Industrial), OMPI (Organização Mundial da Propriedade Intelectual) ou EPO (European Patent Office), juntamente com a revelação e descrição total dos detalhes da sua invenção, acompanhada de uma série de reivindicações, que constituem o cerne da própria invenção e a matéria para a qual se visa obter a proteção legal.

No decurso do processo de registo e concessão da patente, os gabinetes oficiais como o INPI, EPO ou OMPI ${ }^{2}$, irão gerar um ou mais documentos de índole legal que se designam por literatura de patentes. A informação que estes documentos contêm designa-se por informação de patentes.

Após a publicação do pedido de patente essa informação passa a ser de acesso público para quem a desejar consultar. Em troca da proteção por patente concedida para o seu invento por 20 anos $^{3}$, a informação referente à invenção passa a ser de domínio público, podendo essas invenções ser realizadas para fins de investigação (CPI, 2009).

A finalidade desta divulgação visa catalisar a atividade inventiva de outros, tornando possível o avanço da tecnologia que, de outra forma, continuaria a ser mantida em segredo. Visa, também, a constituição de um repositório de informação técnico-científica de modo a que este conhecimento não se perca pelo desaparecimento precoce do seu inventor (ex. fogo Grego, segredos químicos e metalúrgicos, Bombokas, entre outros).

Assim, nos documentos de patente podemos encontrar: i) O 'estado da arte', os conhecimentos técnicos disponíveis até à data na área em que se insere o invento realizado; ii) Tipo e natureza dos problemas técnicos que o invento irá 
resolver; iii) Descrição detalhada do invento e forma como funciona; iv) llustrações, esquemas e desenhos das partes constituintes do invento para mais fácil entendimento (IDRIS, 2003; MAIA, 1996).

Uma das prerrogativas para que a patente possa ser concedida, é que a informação constante do pedido de patente seja de tal forma detalhada que uma pessoa versada na área seja capaz, ela própria, de executar o invento. Isto permite replicar o invento, para fins de investigação, sem qualquer penalização (MARAVILHAS \& BORGES, $2011 \mathrm{a})$.

Os repositórios de informação de patentes são a maior fonte de informação científico-técnica, disponível gratuitamente via Web, a nível mundial. Existem cerca de 70 milhões de documentos de patentes publicados em todo o mundo, contendo a maior parte deles informação não disponível em nenhum outro local (BREGONJE, 2005; GREIF, 1987; MARCOVITCH, 1983) e, mesmo a informação que existe simultaneamente nos documentos de patente e noutras fontes como artigos científicos, relatórios técnicos, atas de conferências, monografias, teses e outras publicações, não está descrita com o mesmo grau de detalhe e demoram mais tempo a serem tornados públicos. De acordo com um estudo recente (BREGONJE, 2005) a informação técnica detalhada contida num documento de patente com cerca de 80 - 100 páginas ${ }^{4}$, não ultrapassa as 20 páginas quando apresentada publicamente em conferências e publicada nas suas atas ou em revistas científicas, sendo a média de apenas 12 páginas. Aí é descrita a ideia e possíveis aplicações mas nunca a forma de realizar o invento, o que é obrigatório descrever no documento de patente para que a sua proteção seja concedida, dotando-o de maior detalhe, mais riqueza de informação, descrevendo o estado-da-arte, citações e contendo o importante relatório de pesquisa realizado pelo examinador de patentes que concedeu a respetiva patente. Além disso, aproximadamente um milhão de novos documentos são criados todos os anos (OMPI e EPO) que após publicação, cerca de 12 a 18 meses após efetuado o pedido, são de consulta pública mesmo antes de ter sido concedida a proteção, o que só acontece normalmente três anos após a data de entrada do pedido de patente.

Sabemos, também, que mais de $30 \%$ das patentes se encontram em domínio público - por terem atingido o limite temporal de proteção ou por falta de pagamento das licenças anuais - ou não estão a ser exploradas por falta de financiamento ou incapacidade técnica do seu detentor (GODINHO, 2003; IDRIS, 2003; MAIA, 1996). Alguns estudos referem que mais de $30 \%$ da investigação em Portugal é redundante (GODINHO, 1999, 2003; RIBEIRO, 2007), o que significa que todos os anos são gastos tempo e dinheiro em investigação e desenvolvimento (I\&D) que não poderá ser patenteada, explorada e rentabilizada pois estaria a infringir patentes já existentes.

Tal quantidade de documentos torna a literatura de patentes a maior fonte de informação tecnológica disponível em todo o mundo, sendo o maior repositório de conhecimento técnico, possuidor de um valor incalculável.

Existem inúmeros exemplos que mostram lapsos de vários anos desde que a invenção é patenteada até que seja divulgada publicamente por outros meios, sendo a documentação de patentes o único lugar onde esta pode ser encontrada antes de ser dada a conhecer pelo seu detentor.

\section{Utilização estratégica e competitiva da informação de patentes}

Muitos documentos de patente cuja validade legal já expirou, podem conter informações técnicas valiosas que na altura estavam à frente do seu tempo, sem meios de serem efetivamente realizadas em termos técnico-industriais ou económicos, ou para as quais os consumidores não estavam ainda preparados (ex. IXI DAP de 1979 originou o Apple iPod de 2003; o Touchscreen de 1965 só teve aplicação comercial na década de 90 do séc. XX, entre outros).

Além da informação técnica contida nos documentos de patente, referente à invenção em si, outra fonte de informação importante, que normalmente é descurada, são os relatórios de pesquisa ${ }^{5}$. O relatório de pesquisa é proporcionado pelo gabinete de patentes onde se requereu o registo e é constituído por uma lista de todas as patentes, livros, artigos de jornal e de revista, atas de conferências, teses, que possam ter alguma relação com o invento em questão.

Também se devem ter em atenção as referências e citações realizadas no pedido de patente pelo requerente pois permitem situar em que grau de desenvolvimento se encontra a área tecnológica onde se integra o invento.

Todas estas informações estão, atualmente, pesquisáveis online, através de sítios na Internet. 
Para IDRIS (2003), as principais razões para analisar a informação de patentes são: i) A informação atualizada contida nos documentos de patentes pode ajudar a evitar investimentos erróneos relativamente à possibilidade de duplicar trabalhos de pesquisa que já foram realizados; ii) $O$ uso insuficiente da informação de patentes tem causado um desperdício considerável de fundos investidos em programas de I\&D cujo retorno está ameaçado pela existência de tecnologia patenteada ${ }^{6}$; iii) Em certas circunstâncias, é possível utilizar a informação de patentes para desenvolver novos produtos e processos ${ }^{7}$. Desde que a nova invenção daí resultante não infrinja as reivindicações (Claims) da patente já existente, esta é uma forma perfeitamente legítima e uma das mais importantes justificações para a existência do sistema de patentes (MARAVILHAS, 2009; MARAVILHAS \& BORGES, 2009).

MARCUS (1995) afirma que, para além dos parâmetros óbvios que se podem encontrar na informação de patentes, tais como, nome do inventor, detentor da patente, datas de prioridade e família de patentes, se o pesquisador usar a sua imaginação pode encontrar uma enorme variedade de informações comercialmente valiosas, como: i) Possibilidade de encontrar e/ou identificar potenciais clientes ou parceiros de negócio; ii) Proporcionar informação de suporte a uma reunião de negócios, permitindo ficar a conhecer o potencial técnico da empresa com quem se vai reunir; iii) Identificar tendências em I\&D, novas tecnologias e novos produtos; iv) Identificar tendências e movimentações entre empresas, podendo indiciar fusões e aquisições; v) Facilitar a transferência de tecnologia ou 0 licenciamento de tecnologia, permitindo adquirir o que a empresa necessita ou vender o que a empresa desenvolveu; vi) Prevenir a duplicação de projetos de I\&D, evitando a cópia; vii) Identificar especialistas num determinado campo tecnológico ou área científica; viii) Estabelecer novas aplicações e utilizações para produtos e tecnologias existentes; ix) Encontrar soluções para problemas técnicos; x) Apoiar a geração de ideias para novos produtos ou processos; xi) Identificar tendências de Marketing; xii) Estabelecer a data de expiração de uma patente, que permitirá a livre utilização dessa invenção; xiii) Identificar potenciais concorrentes; xiv) Monitorizar as atividades dos concorrentes; xv) Estabelecer o 'estado-da-arte' da técnica.

\section{Exemplos de utilização da informação de patentes}

Tendo em conta que a maioria das patentes existentes em todo o mundo já expirou, tendo terminado a sua proteção, não deixa de ser importante consultar esses documentos que, apesar de caducados em termos legais, continuam a conter em si importante informação técnica ${ }^{8}$ (MARAVILHAS, 2009).

Em termos industriais e empresariais, existem um sem número de invenções que não estão a ser exploradas comercialmente ou estão a ser sub-exploradas ${ }^{9}$.

Começaremos pelo exemplo do Velcro, nome comercial de um conhecido material usado para substituir botões ou fechos de correr. O Velcro foi inventado em 1948 por Georges de Mestral, que obteve a patente para esse invento em 1957. Nessa época, a única organização que demonstrou algum interesse no invento foi a NASA que o utilizou nos fatos espaciais dos seus astronautas. Só em finais da década de 60 o seu uso começou a ser generalizado, sendo utilizado como forma de apertar roupas e calçado desportivo.

Atualmente, apesar de a sua patente estar caducada, é amplamente utilizado no mesmo tipo de aplicações demonstrando que existem produtos que continuam a ter aplicação industrial vários anos após expirado o período de proteção da patente não recebendo, atualmente, o seu inventor qualquer compensação monetária pela sua invenção.

Outro exemplo conhecido é o Nylon, polímero sintético de grande aplicação em fibras têxteis, que se caracteriza por ser extremamente resistente e de grande elasticidade. Este produto foi desenvolvido na década de 30 do século XX por um grupo de cientistas dirigido pelo químico Wallace Carothers da empresa DuPont, nos EUA. Ainda hoje se utiliza o Nylon em artigos tão variados como, lingerie, camisas, gabardinas, para-quedas, linha cirúrgica, linha e redes de pesca e, se moldado, em utensílios de cozinha e peças de máquinas industriais. Contudo, a sua tecnologia tem cerca de 70 anos e a sua patente está caducada (MARAVILHAS, \& BORGES, 2009).

O mesmo acontece com a Lycra, Kevlar, Gore-Tex, PVC, Polyester e outros produtos sintéticos em domínio público. 
O Teflon, da Dupont, é um produto com muito baixo quociente de atrito que começou por ser utilizado nas asas dos aviões para evitar a acumulação de detritos que provocavam turbulência e, atualmente, é utilizado nas frigideiras antiaderentes.

Outro exemplo, utilizado em Portugal, diz respeito aos medicamentos genéricos. Estes são a substância ativa de determinado medicamento cuja patente expirou, passando assim a ser de domínio público, passível de ser fabricado e comercializado por qualquer outra empresa, desde que não utilize a marca comercial registada, se ainda em vigor.

Em Portugal, temos os exemplos das empresas Hovione, Generis, Farmoz (Tecnimede), Labesfal, Ratiopharma, GP - Genéricos de Portugal, Bluepharma e Almus (da Associação Nacional de Farmácias - ANF) que consultam esta informação para saber que patentes irão caducar e permitirão fabricar medicamentos genéricos, sem custos de I\&D.

A vantagem para os consumidores é clara: a obtenção de soluções essenciais para melhorar a saúde e qualidade de vida dos cidadãos, a preços mais baixos do que praticados até então pela empresa que teve de reaver o enorme investimento que realizou para a obtenção do produto.

Outro produto bem conhecido é o Aspartame, adoçante artificial desenvolvido pela Searle, empresa posteriormente adquirida pela Monsanto, sendo comercializado com a marca comercial Nutrasweet. Cerca de 200 vezes mais doce do que a sacarose ou açúcar de cana, é utilizado em refrigerantes, sobremesas e como adoçante de mesa. Graças à informação de patentes qualquer empresa pode saber como sintetizar o aspartyl-phenylalanine methyl Ester e, mais importante ainda, que a sua patente caducou em 1992, o que significa que pode ser fabricado e comercializado sob qualquer outra designação comercial, tal como acontece (ex. Candere)).

Outra vantagem proporcionada pela informação de patentes é a utilização de tecnologias para a resolução de problemas de áreas distintas daquelas para que foram patenteadas ${ }^{10}$. A fábrica Cosworth, de motores de alto desempenho, adaptou uma invenção de uma bomba eletromagnética oriunda da área da energia nuclear, para forçar o metal derretido a entrar nos moldes utilizados nas suas fundições em molde tradicional, eliminando o ar que normalmente torna as peças metálicas porosas (TIDD, BESSANT, \& PAVITT, 2003, 266).

Todos os exemplos apresentados levam-nos a concluir que a eficaz utilização deste tipo de informação pode realmente traduzir-se numa fonte incalculável de vantagens competitivas para os utilizadores que dela saibam retirar o conhecimento que implicitamente contém e as integrem em posteriores aplicações que os conduzam a uma situação vantajosa nos mercados em que atuam.

\section{Fontes de informação de patentes na internet}

Diariamente surgem novos produtos no mercado. A estes, segue-se o lançamento de produtos alternativos pelas empresas concorrentes em muito pouco tempo (MARKIDES \& GEROSKI, 2005; SCHNAARS, 1995). São exemplos recentes o touchscreen nos telemóveis (Apple iPhone, Samsung Galaxy, LG Cookie), as máquinas de café com cápsulas (Krups Nespresso da Nestlê" ${ }^{11}$, Delta 'Q'osmo e ALQIMIA, Tassimo da Bosh), SmartPhones (Blackberry, Google Nexus, HTC, Nokia Symbian, Motorola Milestone, Windows Phone 7, Apple iPhone, Boston), Tablet PC (Asus, Acer, Toshiba, Pioneer, Sony, iPad), leitores de Mp3 e Mp4 (Apple iPod, Creative Zen, Mpman, Sony NWZ, Sandisk Sansa, Phillips GoGear), entre tantos outros produtos.

Sabendo que o desenvolvimento de um novo produto demora vários anos (ASHTON \& KLAVANS, 1997; SKARZYNSKI \& GIBSON, 2010), como é possível surgirem no espaço de semanas produtos similares e alternativos? A resposta reside na consulta dos documentos de patente, que permite às empresas monitorizarem as empresas concorrentes de modo a encetarem estratégias que lhes permitam manter-se nos mercados onde atuam sem perderem terreno.

Esta informação deve ser periodicamente consultada, realizando vigilância tecnológica (ASHTON \& KLAVANS, 1997; DANTAS, 2001), para a monitorização dos movimentos dos concorrentes e conhecer os novos caminhos de investigação e as tecnologias que estão a ser desenvolvidas ${ }^{12}$.

Existem inúmeros recursos de informação de patentes, gratuitos, que devem ser consultados para daí retirar todos os benefícios enunciados. A importância da existência deste recurso para a área em análise - a literatura de 
patentes - reside no acesso à informação nelas contida, em inúmeros países onde tais documentos se encontram em formato papel, evitando deslocações onerosas e praticamente impossíveis de realizar.

Se fosse necessário efetuar a deslocação a todos os gabinetes de Propriedade Intelectual (PInt) do mundo de modo a verificar se determinado invento se encontra protegido num dado país, seria impossível em tempo útil e com recursos escassos proceder a essa verificação.

A importância da Internet na disseminação desse tipo de conhecimento é sem dúvida de extraordinária relevância pela sua atualidade e facilidade no acesso e consulta da informação que, desta forma, é disponibilizada a um conjunto de utilizadores mais vasto e, potencialmente, global. Todos estes motivos justificam e tornam válida a existência de recursos gratuitos na Internet, para difusão do saber técnico-científico acumulado ao longo do tempo (CHANDRA, 2002). Estes recursos podem ser oferecidos por serviços comerciais, mas muitos deles podem ser obtidos de forma gratuita. Dos serviços comerciais fornecidos por empresas especializadas na obtenção de informação científico-técnica, salientamos a Derwent da Thomson Reuters, a Lexis-Nexis, a STN, a CAS (Chemical Abstracts Service) e a Micro-Patent, entre outras.

\section{Exemplos de fontes gratuitas de informação de patentes}

A vantagem dos recursos a seguir descritos é que, para além de serem gratuitos - bastando poder utilizar um computador com acesso à Internet - permitem consultar informação de registos de patente dos principais países industrializados, com maior número de invenções e consequentemente de patentes atribuídas como, em certos casos, permitem o acesso aos documentos cujas patentes foram recusadas ou que ainda se encontram em fase de análise. Mesmo recusado o pedido de patente, a informação aí contida é deveras relevante pois contém o que de mais recente se faz numa determinada área do saber (MARAVILHAS, \& BORGES, 2009; 2013).

Começamos pela PatentScope da OMPI onde estão contidos os documentos de patente pedidos via Tratado PCT o que possibilita que um único pedido seja válido nos 146 países que o constituem. A partir de um único ponto temos acesso a cerca de dois milhões de patentes internacionais, desde a primeira publicação na sua origem em 1978. Permite consultar o documento após a sua publicação, cerca de 12 a 18 meses após realizado o pedido. Somente cerca de mais outros 12 a 18 meses, num total de aproximadamente três anos, a patente será definitivamente concedida.

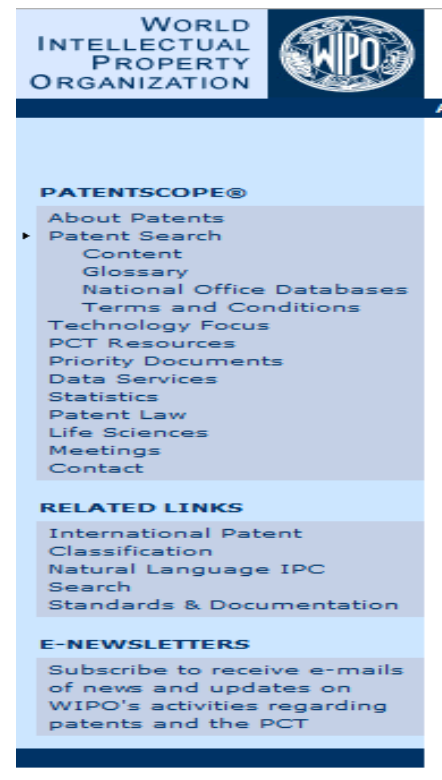
IP SERVICES

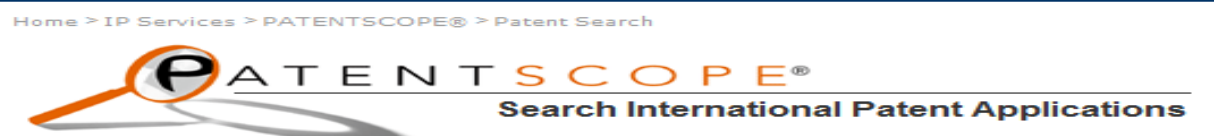

This facility allows you to search $1,530,717$ international patent applications and to view the latest information and documents available to the International Bureau.

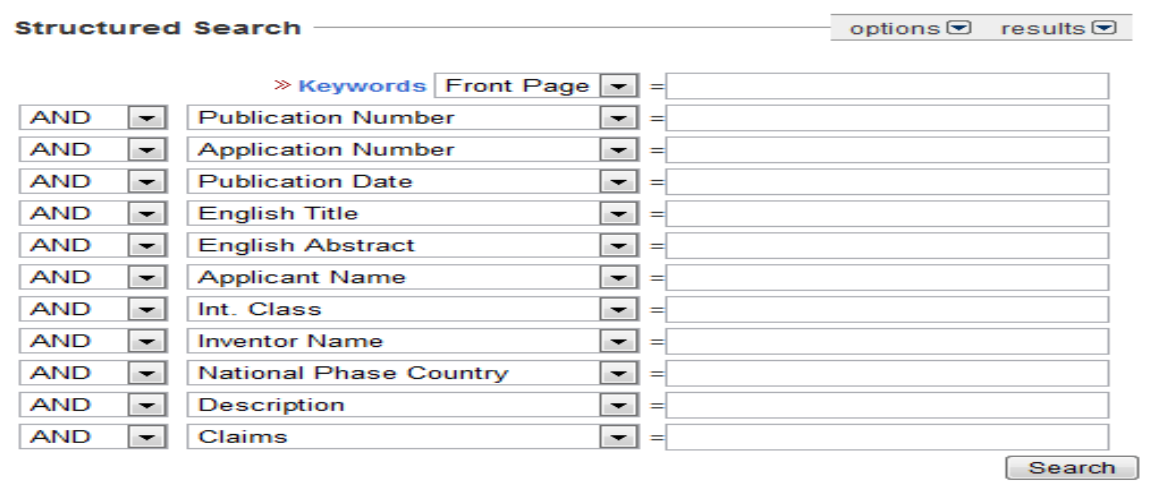


Para as organizações portuguesas, uma vez que se encontra em português ${ }^{13}$, um dos recursos mais relevantes é a Espacenet ${ }^{\circledR 14}$. A funcionar desde 1998, contém as patentes concedidas em Portugal e em todos os países que assinaram o Tratado Europeu de Patentes, via EPO.

Permite o acesso a mais de 60 milhões de documentos de patente, a maioria pedidos de patente ainda em análise, provenientes de 90 países, incluindo a informação do Japão e dos EUA, dos países mais industrializados, dos mais inovadores e com maior número de pedidos de patente todos os anos em todo o mundo. Permite, ainda, o acesso às patentes pedidas via PCT, disponíveis na PatentScope (Cf. Figura 1).
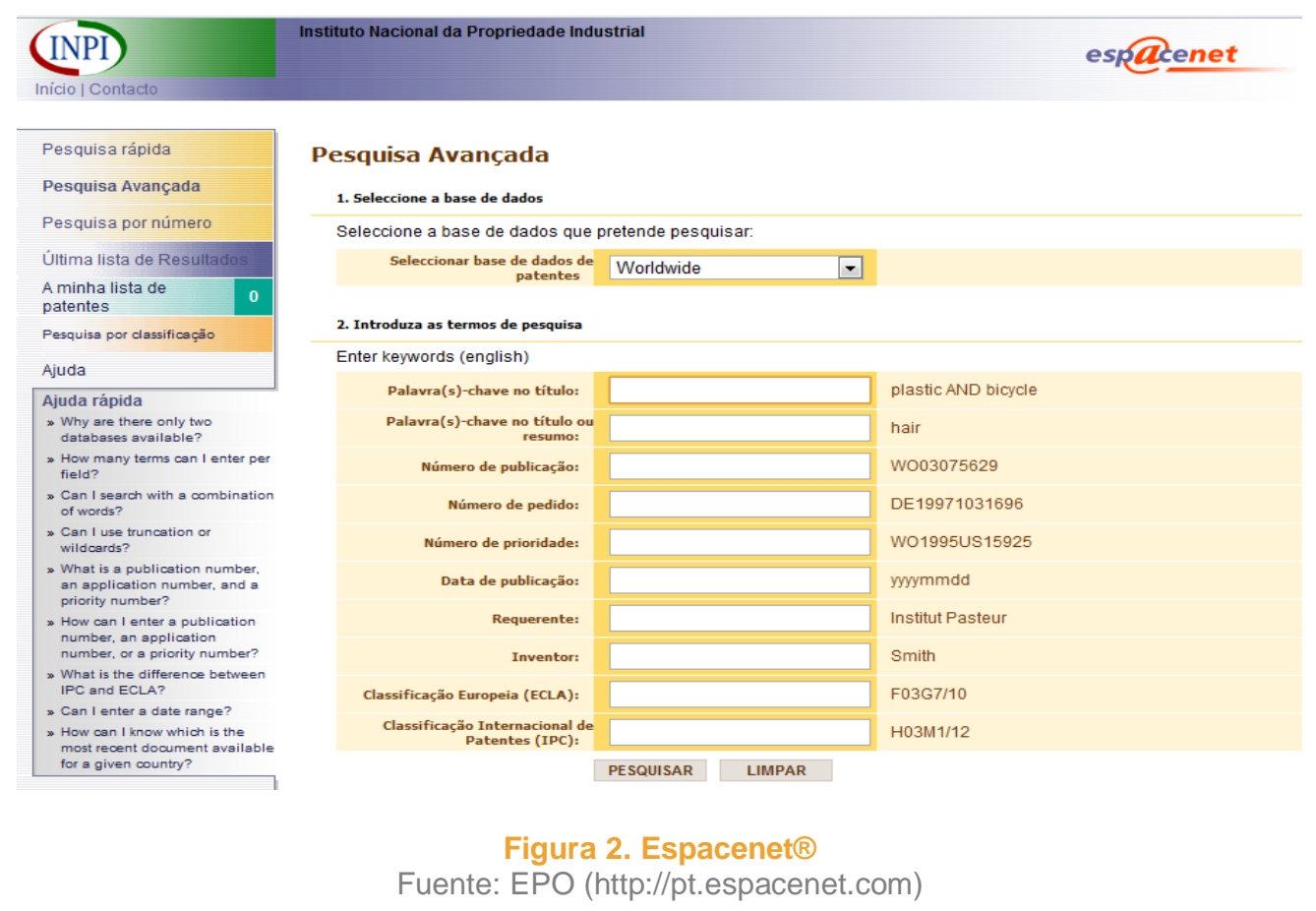

Uma das fontes fundamentais é a informação do USPTO (United States Patent and Trademark Office). Aqui também é possível pesquisar não só os documentos de patentes concedidas como também das que se encontram em análise. A funcionar desde 1976, possui informação que remonta a 1790. Desde 2001 que permite a pesquisa dos documentos ainda antes de a patente ser concedida. É seguramente a maior, considerando um país individualmente. 


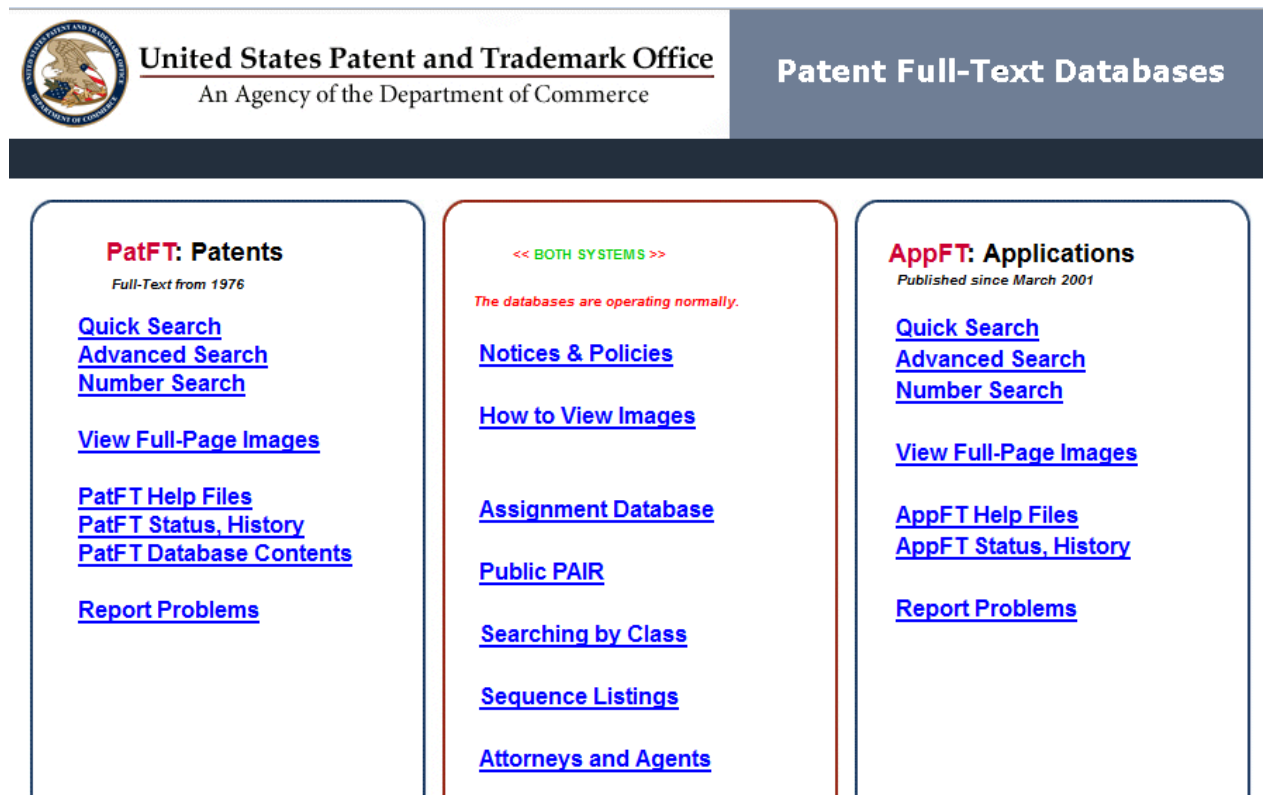

Figura 3: Patent Full-Text Databases - PatFT

Fuente: USPTO (http://patft.uspto.gov/)

Igualmente importante é a IPDL (Intelectual Property Digital Library) que permite o acesso a várias coleções sob a alçada da OMPI, como patentes (PCT e Europeia), marcas e desenhos industriais.

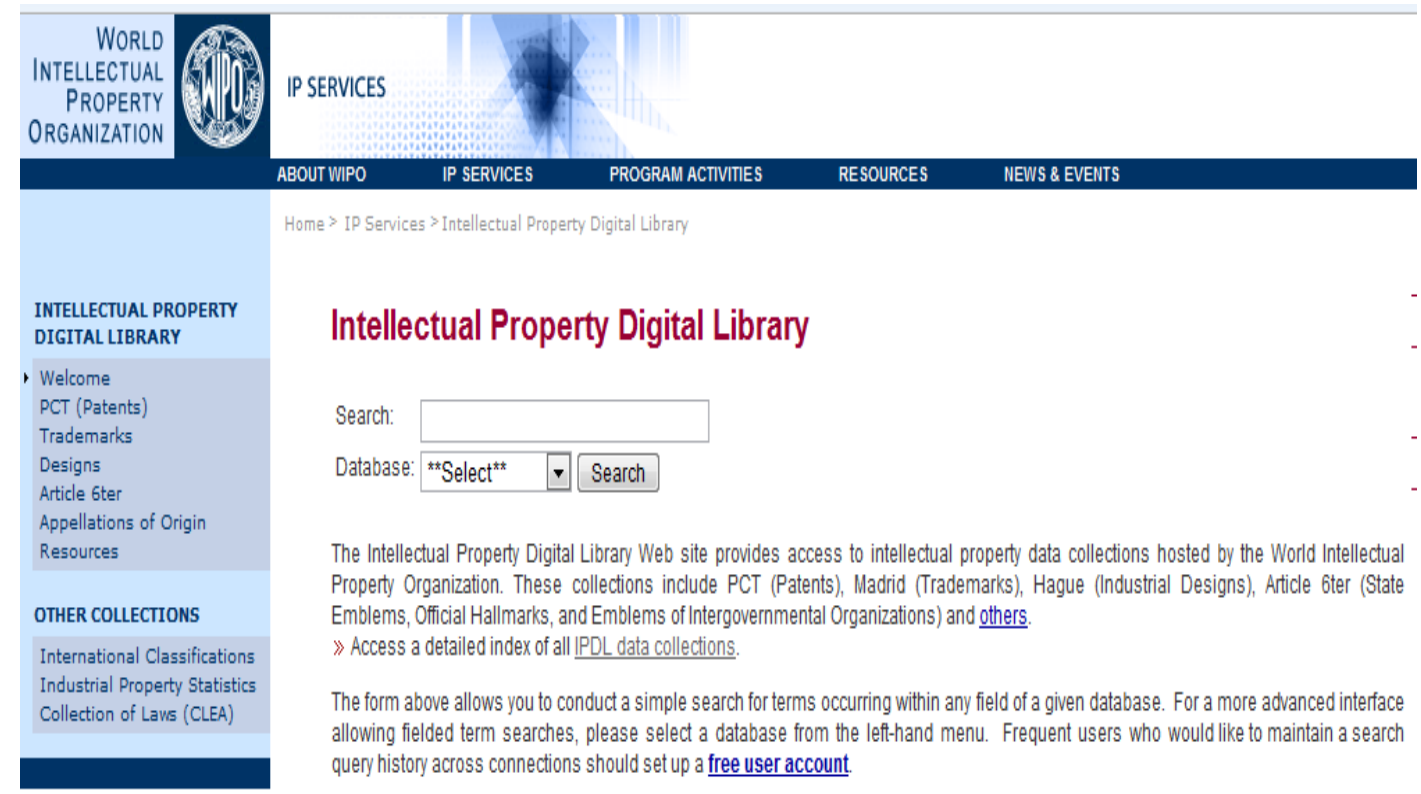

Figura 4: Biblioteca digital - IPDL - WIPO

Fuente: WIPO (http://ipdl.wipo.int/) 
Em Portugal, o Instituto Nacional da Propriedade Industrial (INPI) é o local onde se podem efetuar registos nacionais e pedidos internacionais relacionados com a PI e onde também se pode obter informação a respeito destes pedidos e consultar o Boletim da PI. Permite também o acesso ao interface de pesquisas do Espacenet ${ }^{\circledR}$ em português.

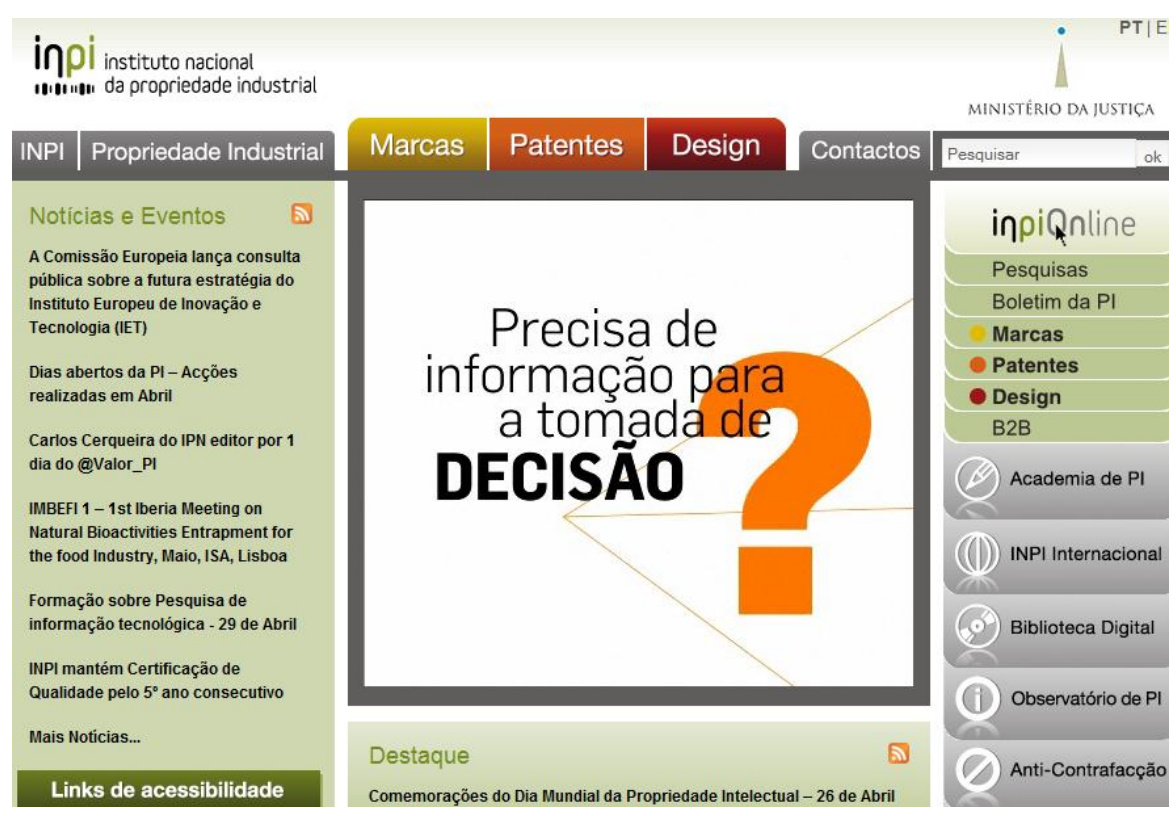

Figura 5: Instituto Nacional da Propriedade Industrial

Fuente: INPI (http://www.marcasepatentes.pt/)

\section{Conclusão}

Analisamos a informação de patentes e a sua importância para o estímulo à criatividade e impulso à inovação, já que aí podemos encontrar vários exemplos de soluções científicas e tecnológicas aplicáveis a outros cenários. Citamos vários exemplos da sua utilização estratégica, donde salientamos os seguintes: i) Usar produtos inventados para uma função mas que adaptados possam servir para outra distinta ${ }^{15}$; ii) Conhecer produtos patenteados que possam ser melhorados, tornando-os tecnologicamente mais avançados; iii) Usar em Portugal produtos e processos que não estejam registados e protegidos no nosso país; iv) Produtos cuja patente já tenha caído em domínio público, como os medicamentos genéricos que usam a substância ativa dos medicamentos cuja patente expirou.

A consulta atenta e eficaz da informação de patentes pode potenciar a tomada de conhecimento atempada de novos produtos ainda em fase de desenvolvimento, podendo permitir a participação de novos atores que contribuam com valor acrescentado para a apresentação final do produto em questão.

Pode permitir, também, a aquisição de direitos de participação e exploração antes da concorrência, ou estabelecimento de parcerias estratégicas.

Outras estratégias passam por elaborar: i) Produtos alternativos ou substitutos - realizar algo que sirva de alternativa a uma tecnologia (nova ou não), usando outros materiais, processos, tecnologias ou recursos para fazer um produto que vá suprir a mesma necessidade; ii) Produtos ou serviços complementares - fornecimento de produtos ou serviços complementares a uma dada invenção e inovação. Realizar algum produto ou prestar algum serviço que venha a permitir uma mais eficaz utilização ou melhor aproveitamento da invenção original; iii) Distribuidores exclusivos e especializados - o inventor e detentor de determinada patente seguramente estará interessado em ter algum parceiro estratégico que o manufature ou produza ao melhor preço e com a melhor qualidade e, também, 
alguém que tenha a capacidade de o colocar no mercado com a melhor margem de lucro possível; iv) Fundamentação legal - a informação de patentes deve ser consultada para descobrir patentes que não estejam a ser exploradas no país permitindo, assim, requerer uma licença obrigatória. Caso exista um produto ou processo patenteado que não esteja a ser explorado pelo seu detentor ou por alguém por ele designado, se houver interesse em proceder a essa exploração pode ser requerida uma licença obrigatória ${ }^{16}$ para o fazer, evitando patentes defensivas $^{17}$.

As patentes cujas taxas não sejam pagas pelo seu detentor (por motivos financeiros ou pessoais), fazem caducar a proteção da patente, caindo esta em domínio público e podendo assim ser usada livremente.

Devemos voltar atrás, àquelas invenções que nunca foram possíveis por não existirem técnicas viáveis e financeiramente suportáveis para serem realizadas (ex. veículos movidos a Hidrogénio e energia elétrica, utilização da energia solar, entre outras). Com o desenvolvimento atual, talvez seja possível serem realizadas com sucesso e permitirem algum avanço tecnológico com vantagens sustentáveis e ecológicas (MARAVILHAS, 2012; 2013).

Podemos, assim, obter informação sobre ciência e tecnologia para estimular o desenvolvimento de novas inovações. Apesar de esta informação estar disponível para todos, nem todos usufruem dela. Não basta detê-la, é preciso construir algo novo com ela.

O segredo do sucesso não está só em saber o que os outros não sabem. Está sim, em agir sobre essa informação e produzir vantagens e benefícios para o seu detentor.

\section{Referências bibliográficas}

ASHTON, W. B., \& KLAVANS, R. A. (1997). Keeping abreast of science and technology: technical intelligence for business. Columbus: Battelle Press.

BREGONJE, M. (2005). Patents: A unique source for scientific technical information in chemistry related industry? World Patent Information, 27 (4), 309-315.

BUTLER, J. T. (1995). Patent Searching Using Commercial Databases. In LECHTER (Ed.), Successful Patents and Patenting for Engineers and Scientists. New York: The Institute of Electrical and Electronics Engineers (IEEE) Press.

CARDOSO, F. (2006). Portugal está no fim da lista no registo de patentes. Diário de Notícias.

CHANDRA, H. (2002). Digital library for patents [Electronic Version]. Retrieved 31-01-2009, from http://eprints.rclis.org/4585/1/naclin.pdf

CPI. (2009). Código da Propriedade Industrial (2ª ed.). Lisboa: Instituto Nacional da Propriedade Industrial.

DANTAS, J. (2001). Gestão da Inovação. Porto: Vida Económica.

DOORNBOS, R., GRAS, R., \& TOTH, J. (2003). Usage profiles of patent information among current and potential users : report on the main results of the survey commissioned by the European Patent Office. Amsterdam: Motivaction.

FLAMMER, R. (2010). Patent Information: Promoting Innovation Through Cooperation. Paper presented at the EPO Patent Information Conference. Retrieved 30-09-2010, from http://www.epo.org/pi-conference

GODINHO, M. (1999). Inquéritos à inovação em Portugal: diversidade de abordagens e resultados. In GODINHO \& CARAÇA (Eds.), O Futuro Tecnológico. Oeiras: Celta Editora.

GODINHO, M. (2003). Estudo Sobre a Utilização da Propriedade Industrial em Portugal (Vol. I). Lisboa: Instituto Nacional da Propriedade Industrial.

GRANT, R. M. (2002). Contemporary strategy analysis: concepts, techniques, applications: Wiley-Blackwell. 
GREIF, S. (1987). Patents and Economic Growth. International Review of Industrial Property and Copyright Law, 18 (2), 191-213.

IDRIS, K. (2003). Intellectual property: a power tool for economic growth. Geneva: World Intellectual Property Organization.

MAIA, J. M. (1996). Propriedade Industrial: Comunicações e Artigos do Presidente do INPI. Lisboa: Instituto Nacional da Propriedade Industrial.

MARAVILHAS, S. (2009). A Informação de Patentes: vantagens da sua utilização como estímulo à criatividade, I\&D, inovação e competitividade das empresas portuguesas. In IAPMEI (Ed.), Parcerias Científicas para a Inovação (pp. 91-110). Lisboa: IAPMEI.

MARAVILHAS, S. (2012). A Informação de Patentes como fonte de ideias para produtos e negócios sustentáveis. Vth GECAMB, Conferência CSEAR Portuguesa de Gestão e Contabilidade Ambiental. FEUC (Coimbra 25 e 26 outubro).

MARAVILHAS, S. (2013). A aplicação de novos conhecimentos para a sustentabilidade com base na informação de patentes. I Congresso ISKO Espanha e Portugal / XI Congresso ISKO Espanha - Universidade do Porto, Novembro 7 - 9, 2013 (http://www.youblisher.com/p/749221-I-Congresso-ISKO-Espanha-e-Portugal-XICongreso-ISKO-Espana/ - pp.800-823)

MARAVILHAS, S., \& BORGES, M. (2009). O Impacto das Bibliotecas Digitais de Patentes no Processo de Inovação em Portugal. In BORGES \& SANZ-CASADO (Eds.), A ciência da informação criadora de conhecimento. (Vol. II, pp. 47-63). Coimbra: Actas do IV Encontro Ibérico EDIBCIC 2009.

MARAVILHAS, S., \& BORGES, M. (2011a). Os recursos de informação usados na I\&D em Portugal: Caracterização dos centros de investigação do ensino superior público das áreas de Ciência, Tecnologia e Medicina. In PULGARÍN GUERRERO \& VIVAS MORENO (Eds.), Límites, fronteras y espacios comunes: encuentros y desencuentros en las Ciencias de la Informacíon (pp. 321-333). Badajoz: Actas do V Encontro Ibérico EDICIC 2011.

MARAVILHAS, S., \& BORGES, M. (2011b). A utilização da informação de patentes pelos centros de investigação do ensino superior público: o seu impacto no processo de inovação em Portugal. In PULGARíN GUERRERO \& VIVAS MORENO (Eds.), Límites, fronteras y espacios comunes: encuentros y desencuentros en las Ciencias de la Informacíon (pp. 364-376). Badajoz: Actas do V Encontro Ibérico EDICIC 2011.

MARAVILHAS, S., \& BORGES, M. (2013). O Impacto da Informação de Patentes no Processo de Inovação em Portugal. VI Encontro Ibérico EDICIC 2013 - Universidade do Porto, Novembro 4-6, 2013 (http://www.youblisher.com/p/745142-VI-Encontro-Iberico-EDICIC-2013-Globalizacao-Ciencia-Informacao/ - pp. 382403)

MARCOVITCH, J. (1983). Administração em ciência e tecnologia. São Paulo: Edgard Blücher.

MARCUS, D. (1995). Benefits of Using Patent Databases as a Source of Information. In LECHTER (Ed.), Successful Patents and Patenting for Engineers and Scientists. New York: The Institute of Electrical and Electronics Engineers (IEEE) Press.

MARKIDES, C., \& GEROSKI, P. (2005). Fast Second: How Smart Companies Bypass Radical Innovation to Enter and Dominate New Markets ( $1^{\text {a }}$ ed.): Jossey-Bass.

RIBEIRO, D. (2007). Propriedade Intelectual: Mais de $30 \%$ da investigação em Portugal é redundante. Jornal de Negócios, Quinta-feira (24 de Maio), 34.

ROGERS, E. (1995). Diffusion of Innovations (4ํㅜ ed.): Free Press.

ROLAND BERGER \& PARTNER. (1998). Estudo Sobre o Grau de Utilização da Propriedade Industrial em Portugal. Instituto Nacional da Propriedade Industrial. Direção de Serviços de Informação.

SCHNAARS, S. (1995). Managing Imitation Strategies: How Later Entrants Seize Markets from Pioneers: Simon and Schuster. 
SKARZYNSKI, P., \& GIBSON, R. (2010). Inovar no Essencial: Transforme o modo como a sua empresa inova (1 ${ }^{\text {a }}$ ed.). Lisboa: Actual.

SLATER, P., TWYMAN, P., \& BLACKMAN, M. (2000). The Smart way for patent information to help small firms. World Patent Information, 22 (4), 337-341.

TIDD, J., BESSANT, J., \& PAVITT, K. (2003). Gestão da Inovação: integração das mudanças tecnológicas, de mercado e organizacionais. Lisboa: Monitor.

\section{Notas}

1 "Large corporations turn to patent information for the purpose of competitor intelligence, market analysis and forecasting, current awareness, R\&D, infringement avoidance, and other reasons" (BUTLER, 1995, 36).

${ }^{2}$ No caso de se requerer proteção via Patent Cooperation Treaty (PCT).

${ }^{3}$ Exceto os medicamentos e produtos fitofarmacêuticos cujo Certificado Complementar de Proteção (CCP) amplia esse prazo por mais 5 anos (CPI, 2009, 121-124 Art.ำ115.ำ e 116. $\left.{ }^{\circ}\right)$.

${ }^{4}$ Por vezes os documentos de patente são tão detalhados que podem conter cerca de 200 páginas como a patente da substância no 50 milhões disponível na Chemical Abstracts Service (CAS) da American Chemical Society (ACS). Cf. World Patent WO 2009/097695 de 13-08-2009 (http://www.cas.org - 04-02-2011).

${ }^{5}$ Usualmente são disponibilizados aquando da publicação da patente, constando na primeira página no caso das patentes concedidas pelo USPTO, ou nas páginas finais no caso do EPO e PCT.

${ }^{6}$ Segundo estimativas do EPO a indústria europeia desperdiça cerca de 20 Biliões de dólares anualmente, motivados essencialmente pela falta de informação de patentes, originando uma duplicação de pesquisas que resultam na reinvenção de invenções existentes, re-desenvolvendo produtos que já estavam disponíveis no mercado e que poderiam ter sido facilmente identificados através da informação de patentes (RIBEIRO, 2007).

7 "[A] Unilever desenvolveu a Ceramides e patenteou a sua utilização para um grande número de aplicações. Contudo, não registou a patente para a aplicação da tecnologia aos champôs, que foi posteriormente concedida a um concorrente" (TIDD, BESSANT, \& PAVITT, 2003, 187).

${ }^{8}$ Para mais exemplos de utilização estratégica da PI, Cf. seis Casos de Estudo realizados pelo autor para o Projeto IP for Innovation do EPO e Comunidade Europeia, disponíveis em http://www.ip4inno.eu/.

9 "A survey reported that $67 \%$ of US companies own technology assets that they fail to exploit (assessed at between US $\$ 115$ billion to US $\$ 1$ trillion). It estimates that about US $\$ 100$ billion is tied up in such idle innovation within the IP portfolios of big companies." BTG International (technology transfer firm) survey, 1998 (IDRIS, 2003, 92).

10 "An example of the use of patent information to locate existing technology which can be used in a new context: Industrial Copolymers Ltd. won a Smart achievement award for a product for waterproofing a roof. An improvement on conventional techniques using three layers of bitumen felt, the product is a formulation including a specific additive which develops a high build, high film thickness coating. The additive used, oxazolidine, was spotted in a 20-year old patent as a potential candidate to achieve this, even though it had been little used in the UK in the intervening years. The coatings are also well-suited to related waterproofing applications such as the treatment of bridges and of carpark decking." (SLATER, TWYMAN, \& BLACKMAN, 2000, 340).

11 "Depois da Nestlé ter comprado a patente original, nos anos 70, o departamento de I\&D demorou mais de uma década a aperfeiçoar a bomba de extração das cápsulas, as próprias cápsulas e outras componentes do sistema que eram necessárias para que ele funcionasse adequadamente. (...) Na verdade, seriam precisos mais 15 anos até que a curva de penetração no mercado passasse da horizontal para a vertical." (SKARZYNSKI \& GIBSON, 2010, 209).

12 "Conclusion: the foundation of today's patent law (Paris Convention) AND the meaning of the word "patent" itself... are all about getting information on new inventions into the public domain. Article I, Section 8, Clause 8 of the United States Constitution, empowers the United States Congress: "to promote the Progress of Science and useful Arts, by securing for limited Times to Authors and Inventors the exclusive Right to their respective Writings and Discoveries." ("Promote the progress of science ..." = "Stimulate innovation ...")." (FLAMMER, 2010).

${ }^{13}$ A Espacenet ${ }^{\circledR}$ disponibiliza uma ferramenta de Machine Translation de inglês para português e o seu inverso. No final de 2011 e com uma duração de quatro anos será alargado a todas as línguas dos países da Convenção da Patente Europeia (EPC), inicialmente em inglês e mais tarde em Francês e Alemão (http://www.epo.org/piconference - 17-09-2010). 
$14 \quad$ Um tutorial da Espacenet ${ }^{\circledR}$ pode ser encontrado em (http://www.european-patentoffice.org/wbt/espacenet/assistant.php). Outros recursos de apoio às pesquisas na Espacenet ${ }^{(B)}$ podem ser encontrados em (http://www.espacenet.com/getstarted/index.en.htm).

${ }^{15}$ Existe um produto, a Ciclosporina, que é utilizado nos transplantes de órgãos para que o organismo não rejeite o órgão transplantado, que não foi inventado com essa função mas, usado, resulta. Também a Varfarina, ou Warfarina, é usada como anticoagulante na prevenção de tromboses e outras patologias cardíacas e, se em doses elevadas, como veneno para roedores (ROGERS, 1995, 150, 151).

${ }^{16}$ Cf. (CPI, 2009, pp. 115 - 120 - Secção IV, Artํ. 105a a 112ํ).

17 "In 1974, Xerox's dominant market position was protected by a wall of over 2000 patents, most of which were not used" (GRANT, 2002, p. 238).

\section{Dados do autor}

Sérgio Paulo Maravillhas Lopes

Pesquisador de Pós-Doutorado (Post-Doc) na Universidade Federal da Bahia, Salvador, Brasil, bolsista do PNPD/CAPES e membro integrado do CETAC.MEDIA centro de pesquisa das Universidades do Porto e de Aveiro smaravilhas@ua.pt

Recebido - Received: 2013-12-06

Aceitado - Accepted : 2014-06-30

\section{(c) E EY}

This work is licensed under a Creative Commons Attribution 4.0

United States License.

\section{ULIS D-Sonk}

This journal is published by the University Library System of the University of Pittsburgh as part of its D-Scribe Digital Publishing Program and is cosponsored by the University of Pittsburgh Press. 